\title{
Measuring the Effects of HRM Functions «Reward, Benefit, and Recognition» and «Performance Management» on Innovation and Entrepreneurship: A Practical Study in Pharmaceutical Organizations
}

\author{
Dr. Mohamed Naser
}

Department of Management

College of Business Administration

University of Sharjah

United Arab Emirates

\section{Abstract}

Purpose- Human Resource Management (HRM) in any organization was and still crucial for innovation and entrepreneurship. An empirical study was examined to scrutinize the effect of some (HRM) functions (polices) on innovation and entrepreneurship to achieve goals of business.

Design / Approach- This article primarily includes two parts. In first part, author reviews the concept of: (HRM) functions, innovation and entrepreneurship in the existing literature. In second part, a questionnaire was conducted on the selected participants. The data were analyzed using demographic, correlation, and regression statistics.

Findings- The results show that the mentioned functions of (HRM) are significantly related to perceived innovations over time. Rewards, benefits, and recognition have statistically a moderate effect on perceived innovations then entrepreneurship. While performance management has statistically a good effect on perceived innovations then entrepreneurship

Originality/Value- The basic objective is to measure precisely the effect of each function of (HRM) on innovation and entrepreneurship. A research model was developed and tested. Besides, the role of endogenous forces including change acceptance culture and the power of link between perceived innovations were also considered as important elements in designing the relationships. The practical contribution of this article is that the results would help to choose the best mix and investment between (HRM) functions, which would significantly contribute to the success of innovation and entrepreneurship. Specifically, the understandings of whether those current (HRM) functions in this sector are more or equal or less innovative than other functions to identify the appropriate skills, resources, and plans.

Keywords: Innovation, Entrepreneurship, Human Resource Management (HRM), United Arab Emirates (U.A.E).

\section{Introduction}

Organizations need to create an environment of possibility, a healthy culture where the human resource feels empowered to explore and to share ideas and where there is no fear of consequences. This environment of possibility introduces a new approach to bridge between needs and desires. Change is a necessary part of the human condition. When you look at a newspaper headline or hear about a new behavior that human resource are engaging in, step back, look again, and measure for each without jumping to judgment. In business, we mark these moments of change as successful innovations.

However, its primary objective and that of the human resource operating in any business is to ensure that each organization recognizes and benefits from the next strategic change. The first tasks are framing the innovation and entrepreneurship challenge with the strategic objective of integrating, unleashing and accelerate

\footnotetext{
* This article was submitted in September 2019, and accepted for publishing in December 2019, Published: June 2020.
}

(c) Arab Administrative Development Organization- League of Arab States, 2020, pp 297-310، DOI: 10.21608/aja.2020.88349 
the sensitivity, imagination and capability of innovativeness into business functions of the organization. In the organization ecosystem, most likely to begin with the (HRM) functions (policies or practices) which capable to generate new revenue models. So, it necessitates a new mindset for innovativeness: where can we find the competence and ability to innovate behavior outcomes? (Manu, 2010).

\section{Historical Examination:}

The literature review shows that the relationship between (HRM) and innovation has been defined in many ways. From the perspective of a particular innovation, the organization that generates and implements a novel idea is known as the innovation creating organization, whereas the organizations that later adopt the innovation are considered to be the innovation adopting organizations. Innovation creating organizations are distinguished from innovation adopting organizations for a particular innovation because they successfully initiate, develop, and disseminate new products and technologies (Damanpour \& Wischnevsky, 2006). It should be noted that one organization may serve as the innovation creating organization for one innovation and as an innovation adopting organization for others (Gambatese \& Hallowell, 2011). However, over the last decades there are many articles started to support empirically the positive role of (HRM) in fostering innovation such as (Wang, 2003; Shrivastave \& Shaw, 2004). Some studies (such as: Boston Consulting Group, 2006) suggests that although the importance of (HRM) functions are fully realized by most organizations, and they continue to spend more and more on innovation and entrepreneurship activities, but many of these initiatives did not generate high profits or competitive advantages. Same meaning and results in parallel studies revealed that; while implementing innovation creation is not an easy task, and being a pioneer will not necessarily result in competitive advantage and better profit (Szymanski, Kroff, and Troy, 2007; Zhou, 2006).

In organizations where innovation is the driving force, integrated reward system stimulates (HRM) to take risks, generate new ideas, develop successful products...etc. The literature (Gomez-Mejia et al., 2004) also proposes the use of incentives; the empirical results support this proposition (Laursen \& Foss, 2003). More developed studies found that, the relationship between process innovativeness and performance was enhanced by high levels of climate for personal initiative and psychological safety (Anderson et al., 2014). In this connection, reward structure is mostly important. While idea generation and radical innovations are influenced by individual rewards, incremental innovations and innovation implementation depend on the group rewards. Along with (Saleh \& Wang, 1993), innovative organizations created a motivating reward system that provided public recognition and financial bonuses, suggestion schemes, «dual ladder» system, and so on. In view of that, several organizations have created in house reward systems that motivated (HRM) to achieve goals of innovation and organization as well. Also, benefits and recognition have been put forward in the literature to encourage innovation and entrepreneurship (Mark \& Akhtar, 2003). Scholars have come to realize that different skills, resources, and cultures are needed to encourage innovations (Pérez- Luño, Wiklund, and Cabrera, 2011).

Regarding performance management, many early authors stressed the importance of using it, both in theoretical and empirical studies (Mumford, 2000; Mark \& Akhtar, 2003; Wang \& Zang, 2005). (Baer \& Frese, 2003) explored innovation as an antecedent of performance at the organizational level. At the same time, others proved it clearly that innovation creation would lead to better performance (Langerak \& Hultink, 2008; Zhou, 2006). What is still under test is whether the performance focus should be: performanceoriented or results- oriented or both.

As a consequence, many regional and national governments as well as international organizations have increased their different investments (and (HRM) was one of the interested areas) in innovation-based policies (Mikel Navarro et al., 2009). Thereafter, explaining the effect of (HRM) functions are still in progress from different perspectives (Kemp, RGM. et al., 2003; Loof and Heshmati, 2002; Van der Panne et al., 2003; Du Preez and Louw, 2008; Mothe, and Nguyen-Thi, 2012). Some just indicated that, (HRM) functions are a dominant to achieve innovation and entrepreneurship (Griffiths \& Fred, 2015). As a result, suitable strategies and well-planned systems are vital to enable organizations to excel in their innovation endeavor (Popadiuk \& Choo, 2006).

Therefore, this article aims to distinguish some granted functions behind (HRM)'s transformation toward innovative and entrepreneurial concepts to achieve the goal of business. So, author's challenge is to measure the effect (power of link) of (HRM) functions: (1-Rewards, Benefits, and Recognition 2- Performance Management) on innovation and entrepreneurship, by considering the vital role of change acceptance culture in supporting this adaptation. Initially and by conducting a formal survey, author is going to 
present an evidence of the above mentioned relationship through means of descriptive statistics. Subsequently, will measure the effects that might be having through a regression analysis. The results will deepen our understanding of each (HRM) function (policy) in the pharmaceutical organizations. Specifically, the understandings of whether those current (HRM) functions in this sector are more or equal or less innovative than other functions to identify the appropriate skills, activities. The practical contribution of this article is that the results would help to position (HRM) in a more strategic role for other initiatives.

\section{Theoretical Background HRM functions (policies) and organizational culture from innovational and entrepreneurial perspective}

With the beginning of current century, organizations are forced to accelerate their rhythm of innovation and then entrepreneurship. This can be made through different mechanisms: 1- By internal activities of research and development (R\&D). In relation to the activities involved, most scholars from technology/ science-based studies concur that (R\&D) is a fundamental management which leads to successful innovation (Czarnitzki \& Thorwarth, 2012; Filippetti \& Archibugi, 2011). However, not all innovation is the result of R\&D activities. Or, 2- Through external sources of knowledge such as universities and suppliers...etc, during collaborative agreements which become a common strategy of sharing and transferring the knowledge across organizations to create innovation (Schelling, 2008). 3- By the best combination of 1 and 2. In other words, the scope and scale of innovation is growing at a pace that makes it all but unthinkable that any single organization can do it all themselves. By which elements should be retained internally vs. which ones can be outsourced? In this context, starting point is striking the right balance between in house R\&D and leveraging external innovation.

Culture here refers to encouraging (HR) to challenge the way they do things and generate creative ideas. It implies building an organization culture that doesn't punish risk takers. Any ambitious organization needs to recognize and adopt this, and has to lead its teams and managers in a way that encourage a healthy amount of risk without losing control of the big picture. Here author also need to differentiate the organizational culture and climate as main components to foster (HRM) contribution in innovation and entrepreneurship. Despite earlier calls for greater research attention (such as: Janssen, Van de Vliert, and West, 2004), some studies have addressed the role of culture in innovation. In common with related studies, previous research has consistently found that a culture and climate supportive of innovation are conducive of organizational innovation (Jung et al., 2008; Patterson et al., 2005). Indeed, (Lawson \& Samson, 2001) identified four resourceful elements of organizational culture and climate: a) tolerance of ambiguity by bringing manageable level of uncertainty, putting tight control over project milestones and initiating effective information management; b) empowerment of employees by investing and respecting in employees ability and exceptionality; c) allocation of creative time by allowing flexible deadlines and permeable environment and; d) knowledge sharing and communication among within the organization and its network by means of cross-technological, cross-hierarchical, and cross-functional exchanges.

Nonetheless, the top challenges in managing innovation are: creating and sustaining a culture in which innovation can flourish. This includes a physical and organizational space where experimentation, evaluation, and examination can take place. Also values and behaviors that facilitate innovation have to be developed and sustained. Ultimately, developing (HR) who can flourish in that environment, (HR) who can question, confront, suggested ideas, and apply it as part of a group with a common objective, unconstrained by the day to day operational environment.

Hence, favorable organizational structures and supportive systems helpful to innovation system should be developed by the managers to increase the scope of innovation within organizational sphere. Accordingly, innovation and entrepreneurship success is vitally conditioned by the organizational culture, climate, and structure (Razavi \& Attarnezhad, 2013).

To recognize the up to date functions, author need to begin with (HRM) from innovational and entrepreneurial perspective. Historically, Human Resource is the segment of a business that recruits, trains, and develop an organization's employees. Thus, it is the management in any organization which responsible for: staffing, training, compensation and benefits, career management, and performance appraisal. Human Resource referred to as: (HR), human capital, casting (Disney term), or personnel (Mariotti \& Glackin, 2012). When organizations 
convert to produce innovative outputs, such as: introduce new products, new process, new administrative practices, and new approaches...etc; it's required to recruit a new type of employees. Actually, it call for unique employees who are: flexible, risk taking, and tolerant of uncertainty \& ambiguity (Chen \& Huang, 2007).

Within complicated situation of investment and more anxiety toward environment challenges, (HRM) has to take over the dominant responsibility of innovational and entrepreneurial activities. Thus, (HRM) needs not only to influence on performance, but also to be a real partner and change mentor toward innovation and entrepreneurship (Rayen \& Ani, 2014). However, conclusions of achieving innovation and entrepreneurship will depend on organization's different resources. Different arguments such as (Kobe \& Goller, 2014) revealed that, sustainable innovation requires a combination of long term and balanced relationships between stakeholder's desires and organization abilities. In line with (Jiménez-Jiménez \& Sanz-Valle, 2005; Dan Dalotă \& Perju, 2010), there are no best (HRM) functions, because in order to be effective, (HRM) functions must be consistent with other aspects of the organization, specifically its strategy. The most suitable (HRM) functions for organizations which are trying to develop a competitive advantage based on innovation and entrepreneurship would be different to those functions suitable for organizations seeking other types of competitive advantage. Consequently, some studies have focused on some isolated (HRM) functions while others have focused on the (HR) system which proposed by well-known experts, specialists, and adopted by the successful organizations.

(HRM) functions should be designed and anchored in terms of: centralization or decentralization and horizontally or vertically based on innovation and entrepreneurship requirements. On the whole, the most known, agreed, and up to date functions or policies of (HRM) (Rayen \& Ani, Op Cite; Akili, 2005) could be suggested as follow:

1- Recruitment and Selection.

2- Research, Training, and Development.

3- Reward, Benefits, and Recognition................Current article

4- Career planning.

5- Employees Engagement

6- Performance Management Current article

It is clear that; the author already tested rest functions (Naser, 2017). Here author embarks to measure functions (3+6) of (HRM) as independent variables to define exactly how it affects on perceived innovations (Incremental and Radical) and then entrepreneurship. The key matter is: how far organizations explore and consider the prescribed functions (reward, benefits, and recognition \& performance management) in its early stages in terms of potential impacts which might have on achieving innovation and entrepreneurship? And how far organizations are able and prepared to modify, ameliorate, and possibly abandon, activities that enclose negative effects on innovation spirit?. Under the same spot; innovative organizations carefully analyze (HR) needs and implement integrated rewards, benefits, and recognition systems to recognize then boost innovation and entrepreneurship. Besides, majority of successful organizations put into place sufficient performance systems.

\section{Innovation and Entrepreneurship: A Millennial Poster}

Change is a necessary part of the human condition. In business, we remark these moments of change as successful innovations. Innovation is driven by the ability to observe connections, to spot opportunities, and to take advantage of them. Moreover, being the first who apply and introduce it to the market through entrepreneurship.

Innovation is more than simply coming up with good ideas. For a better understanding of innovation, (Bonazzi \& Zilber, 2014) developed a conceptual review based on major authors who approached it in order to highlight its definitions and evolution of the innovation concept. They also stated that, the contemporary approach to innovation unlinked the interdependence of innovation from the domestic environment, this being increasingly linked to organizational externalities which later came to be known as open innovation (Chesbrough, 2003). In the concept of open innovation, previous resources to innovation extrapolate the organization's environment and are allocated to customers, competitors, business partners, external R\&D, and other entities holding valuable information for the development and implementation. Drawing upon this logic, author argue that innovation is a must for organizations to advance their manufacturing and service delivery to achieve superior performance in order to deal with turbulence in the external environment. 
Also, it is difficult to identify the boundaries and to determine where one innovation stops and where another innovation begins (Jiménez-Jiménez \& Sanz-Valle, 2011; Nor'Aini Yusof et al, 2014).

How we will ensure that the efforts have been justified? Or the big question is, of course, how to make it happen? This has been the subject of intensive study for a long period of time (Schumpeter, 1950; Freeman, 1982; Porter, 1990; EU, European Commission, 2004; Drucker, 2007). This includes knowledge about the kind of things which influence and hinder/ help the process and creating the organizational conditions to allow focused creativity. The end effect is that we have a rich set of receipt which go a long way towards helping answer the practicing manager's question when confronted with the problem of organizing and managing innovation as well as entrepreneurship. The critical point facing any organization is to try and find ways of managing this process to create a solution to the problem of renewal. Different circumstances lead to many different solutions. For example, large science based organizations like pharmaceutical organizations tend to create solutions which have heavy activities around formal (R\&D), patents searching, and so on, whilst small engineering subcontractors will emphasize rapid implementation capability.

Innovation has been construed as a cure-all medicine for all kinds of issues those organizations faceincluding ensuring profitability, revenue growth, loyal customer base, and increased efficiency. This is because innovations are believed to be necessary if an organization must succeed in today's turbulent market (Adner, 2012). Innovation is becoming a central plank in national economy policy for many countries: Sweden, U.A.E., and UK. For example, the UK office of Science and Innovation sees it as the motor of the modern economy, turning ideas and knowledge into products (goods and services). The growth question poses a problem for established players, but a huge opportunity for new comers to rewrite the roles of the game. If we include the newcomers like: Tata, Narayana Hospitals alongside Apple, Google, and Amazon. The nature of innovation is that, it is fundamentally about entrepreneurship which enables bizarre ideas to become a reality. Entrepreneurship mixes strategy with the passion to take risks and change things may not be around creating instant values (Jones et al., 2012; Tidd \& Bessant, 2014). As pioneers realized, entrepreneurship appreciated better than most that the real challenge in innovation was in making all components (Human capital, Systems, Tangible and intangible resources) work technically and commercially. But, not all innovation is about making money, many practical examples of entrepreneurship in which the primary aim is to create some form of social value to make a difference to the world. As a consequence, (Fauchart \& Gruber, 2011) provided the motivations and underlying psychological drivers amongst entrepreneurial founders of business and found three distinct types; 1- Darwinians: primarily concerned with competing and creating business success, whereas 2-Communitarians: much more concerned with social identities which related to participating in and contributing to a community. 3- Missionaries: had a strong inner vision, a desire to change the world, and their entrepreneurial activity was an expression of this.

Based on the above, innovations vary widely, in scale, nature, degree of novelty and so on, and so do innovating organizations. For the purposes of the article, author will continue based on 4 broad categories '4Ps' (Francis \& Bessant, 2005):

- Product Innovation: changes in the products which an organization offers;

- Process Innovation: changes in the ways in which products are created and delivered;

- Position Innovation: changes in the context in which the products are introduced;

- Paradigm Innovation: changes in the underlying mental models which frame what the organization does. It suggests how these '4Ps' provide the framework for a map of the innovation space available to any organization. Examiners and experts have distinguished between different scales for innovations. Among that, radical innovation versus incremental innovation, has received much attention from researchers who are interested in organization redesign and dynamic capability. On the whole, Innovation could take many forms as Figure 1 shows.

The area indicated by circle is the potential innovation space within that organization can operate and where it might move in the future. In the article context, this approach can be used to look at where the organization currently has innovation projects and accordingly let (HRM) construct for innovation strategy. Also, had the completed 4Ps framework had the effect of enlarging choice of (HRM) to think in a systematic way about synchronize using the innovation capabilities of the organization. Organizations have seen that the scope for innovation is wide with both incremental and more radical options. Experts have also looked briefly at the critical role which knowledge plays in managing these different forms. All that provides a feel for what inno- 
vation is and why it matters. But what author now needs to do is measure how some (HRM) functions would sustain the innovation process itself. That's the focus of the rest of article.

Most of the time, innovation takes place within a set of rules which are clearly understood, and involves players trying to innovate by doing what they have been doing the 4Ps but better. Some cope with this

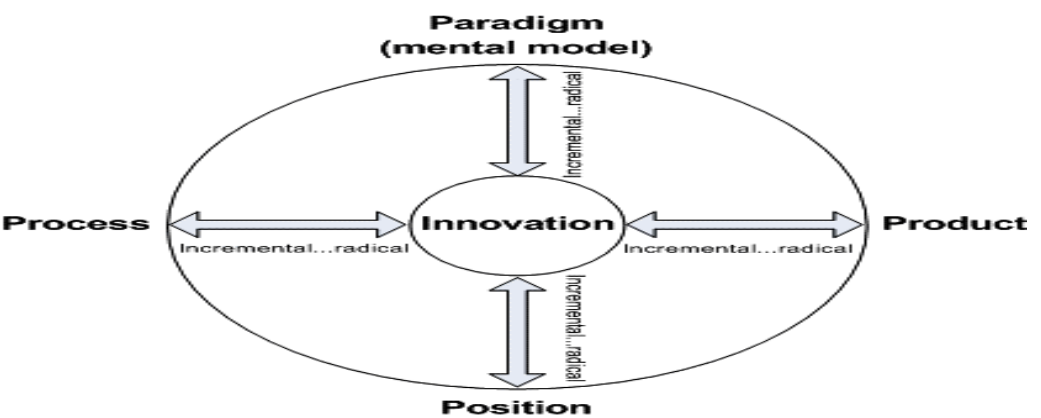

Figure. 1 The 4Ps of Innovation Space more effectively than others. But occasionally something happens which dislocates this framework and changes the rules of the game. As for granted, these are not every day events, but (HRM) have the elasticity to redefine the space and the boundary conditions; here (HR) is ready to open up new opportunities (Philips et al., 2006; Leifer et al., 2000; O`Connor et al., 2008). This is a central theme in Schumpeter's theory about innovation and entrepreneurship which he saw as involving a process of 'creative destruction' (Schumpeter, Op Cite).

One of the keys to success for an innovation-focused organization is the ability to learn and manage innovation. So far, innovation is about knowledge; creating new possibilities through combining different knowledge sets. The process of weaving these different sets together into a successful innovation is one which takes place under highly uncertain conditions. Managing innovation is about turning these uncertainties into knowledge effectively a balancing act. Organizations also need to recognize that innovation opportunities change over time. In modern industries like today`s biotech, Internet software, Nano materials...etc, there is huge scope for experimentation around new product. But many mature industries tend to focus more around process innovation or position innovation, looking for ways of delivering products more cheaply or flexibly, or for new market segments into which to sell them.

\section{Success and Future of (HRM), Innovation, and Entrepreneurship}

Author's position is that, innovation is not a process but an outcome. More precisely; innovation is the moment of witnessing (HR) behavior as outcome has been changed by a unique event or discover which is referred to as an innovative object. This position challenges the current understanding of (HRM) toward innovation and entrepreneurship, as well as the current ecology in which innovation operates in organizations; its management, methods, functions (policies), and goals.

Before moving to the practical part, author should pause for a moment and delineate what do i mean by success of the above (trilogy) and what are the future perspectives. One aspect of this question is the need to measure the overall process rather than its constituent parts. Many successful inventions fail to become successful innovations, even when well planned (Hobday et al., 2005). Equally, innovation alone may not always lead to business success. Although there is strong evidence to connect innovation with performance, success depends on other factors as well. Moreover, there is a need to consider the time perspective. The real test of innovation success is not a one-off success in the short term but sustained growth through continuous amelioration and adaptation. It is relatively simple to succeed once with a lucky combination of creative ideas and receptive market at the right time, but it is quite another thing to repeat the performance consistently. In author terms, success relates to the overall (HRM) functions and its ability to contribute every time to the next innovation. Only pioneer organizations have the foresight to understand what desires, wants, and needs are likely to plan next, given the right functions.

In innovation and entrepreneurship concepts, most resources can be purchased when needed. But (HR) are typically developed internally (even externally) by the organization over time. To have the utmost performance of (HR) entails the organization not only to hire today for a task that is required in two or three years, but also to maintain the value of (HR). So, organizations are involved to keep educating (HR) (Bruton \& White, 2011). Hence, the challenge is no longer about adding value, but about creating value. When employing innovation as strategy, (HRM) needs to be less concerned about what people are doing now, and more distressed about what people are about to do. Based on that, the field of any true business opportunity is in the future. And any step taken forward a designed future requires agility as a measure of the organization 's performance.

Effectively appraising and rewarding performance is central to any valuable and successful (HRM). Many research evidences suggest that; the organizations that have some sort of performance management 
systems have achieved overall better financial performance than those that have not. There are three ways of measuring organizational performance. Generally applied measures are: 1.productivity 2.organizational effectiveness, 3. industry ranking. Here, Peter Drucker (the well-known management guru) was of the view that an organization's employees need to see the connection between what they do and the outcomes. But before followers can see this connection and work toward achieving high performance, managers need to specify the performance outcomes that will be measured. At this point, there are strengths and weaknesses in using experience as a way of capturing the most appropriate approach. For that purpose, benchmarking could present a range of techniques which involve comparisons; for example between two variants of the same process or two similar activities, so as to provide opportunities for learning (Stapenhurst, 2012). Thus, it offers a powerful focus for the future of scenarios in capability models.

\section{Research Limitations}

Like any human effort, this article has several limitations that must be acknowledged, but at the same time it inspire some potential pathways for future research.

First, it uses a cross sectional set of data collected at one time to measure the effect between some (HRM) functions in innovation and entrepreneurship. It might be impact inferences about casual effects between variables.

Second, the generalizability of the article may be limited because the sample is restricted to emirates pharmaceutical organizations or organizations that are exposed to U.A.E. management styles so that the generalizability of the findings might be hindered (Chang \& Chen, 2011).

A third limitation is that of adopting only subjective measures of employees reward, benefits, and recognition and organization innovation and entrepreneurship. This imperfection has been accepted from prior articles, as it wouldn't be not an easy to compare objective measures of performance (Aryee et al., 2012; McClean \& Collins, 2011).

Last but not least, a fourth limitation is the duration and destination. 01/09/2018 till 01/08/2019 is the time limitation. U.A.E. is the destination of field study.

\section{Research Model and Hypotheses}

Innovation is inevitability for many organizations to struggle in the current market confusion, and thus innovation strategies are becoming increasingly crucial for organizations to improve their innovative performance. Accordingly, measuring the power of link between (HRM) functions on innovation and being an entrepreneurship is the bed rock of current article.

\section{Hypotheses}

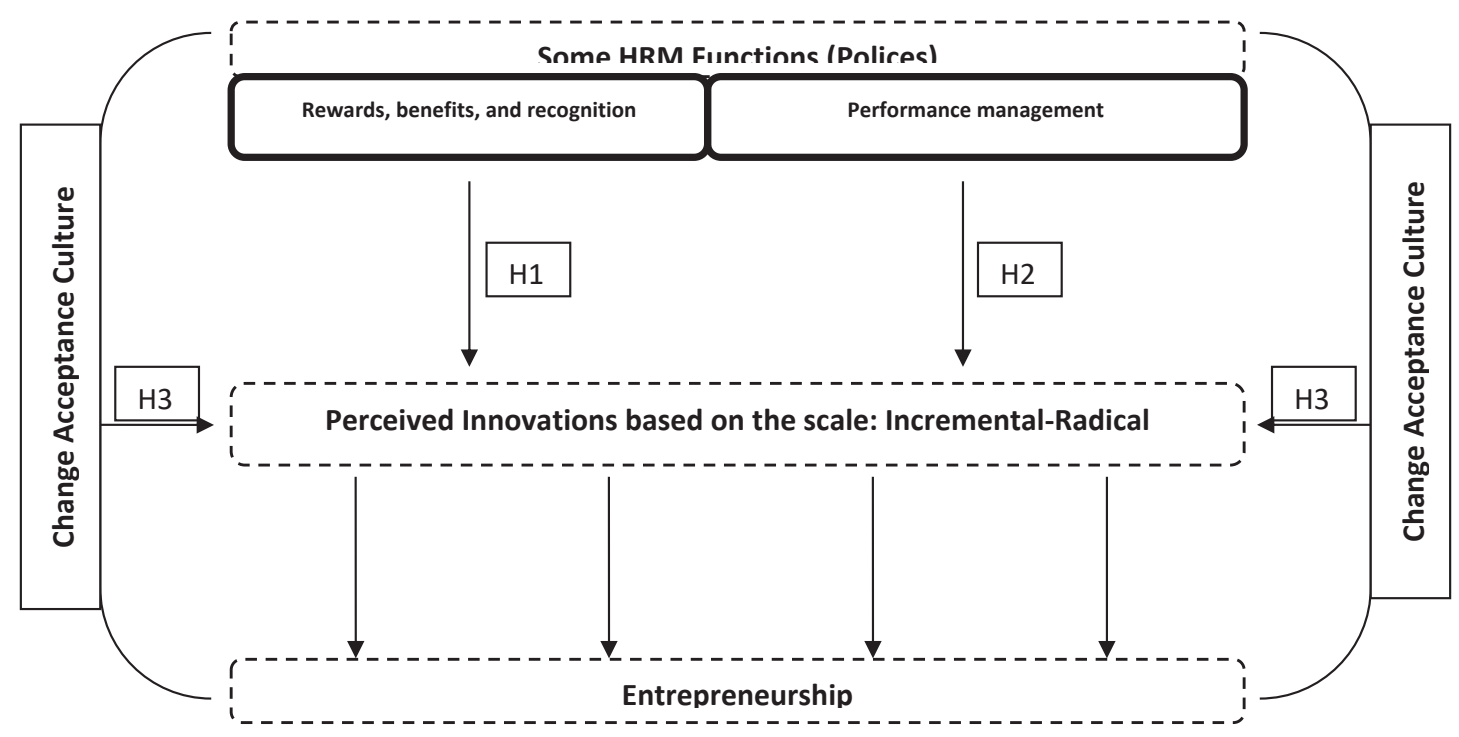

Figure.2 Research Framework 
- H1: Human resource functions (rewards, benefits, \& recognition and performance management) through change acceptance culture have statistically a significance effect on perceived innovations (radical and incremental) then entrepreneurship. This main hypothesis can be divided into the following:

- H2: Rewards, benefits, and recognition have statistically a moderate effect on perceived innovations (radical and incremental) then entrepreneurship.

- H3: Performance management has statistically a strong effect on perceived innovations (radical and incremental) then entrepreneurship.

\section{Methodology}

Derived from the nature of article and its primary purpose to examine the degrees of effect between (independent impacts) some functions of (HRM) and (dependent impact) innovation and being an entrepreneurship to achieve strategic goals of business; The author used both: the descriptive methodology by reviewing the literature related to article variables, and analytical methodology by analyzing the data collected through questionnaire which was distributed and consisted of two parts:

- $\quad$ Part (A) covered the demographic variables, for instance gender, age, education ...etc.

- Part (B) covered the elements (variables) of research model. The answers of part (B) were built on Likert's Scale, ranging from strongly disagree (1); disagree (2); moderately degree (3); I agree (4); and strongly agree (5). Some items were adopted from (Suhag et al., 2017; Nasser \& Abuzaid, 2014).

\section{Data Collection, Sample, and Analysis Technique}

The idea behind innovative and entrepreneurial organizations is to support the approach toward: new, different, and best. In order to accomplish that, data was collected from population of (11) Emirates pharmaceutical organizations that producing (manufacturing) drugs and medications out of (16) organizations which located in this industry (sector). Where there is (1) organization rejected due to inaccurate data.

The size of study sample was applied on (106) out of total respondents (121) who are working within or responsible for: Innovation, (R\&D), and (HRM) to have a high level of authenticity. Obviously, overall response rate was measured $(87,6 \%)$. Through SPSS/PC v. 21 software data was analyze and then results are declared in the following tables.

\section{Research Findings}

\section{Instrument's Reliability and Validity}

In order to ensure the quality of findings and conclusions of the article, both validity and reliability are assessed. Table 1 provides the feedback of these tests.

Results demonstrates that all cronbach`s alpha scores $>60 \%$. It mean the internal reliability between different variables and items were high, stable, and effective (Sekaran \& Bougie, 2013). The acceptable result of reliability analysis allows author to continue research study for further procedure.

\section{Demographical Statistics}

The following table 2 helps in explanation respondents frequencies demographically in percentage.

Previous table illustrates that majority of respondents participated in this study $(72,6 \%)$ are male. Respondents have different age, education, and experience. Table shows that $(29,3 \%)$ are below (25) years age which means emirates pharmaceutical organizations are depending on new blood to support the change and innovations. (66\%) have only graduate background and (34\%) are post graduate.

\section{Data Presentation}

In descriptive examination table 3 mean shows the average distribution; here all values are greater

\begin{tabular}{lccc}
\multicolumn{4}{c}{ Table 1- Reliability and Validity } \\
\hline \multicolumn{1}{c}{ Variables } & $\begin{array}{l}\text { Number } \\
\text { of items }\end{array}$ & $\begin{array}{c}\text { Cronbach`s } \\
\text { alpha value }\end{array}$ & $\begin{array}{c}\text { Validity } \\
\text { value }\end{array}$ \\
\hline $\begin{array}{l}\text { Rewards, Benefits, and Recog- } \\
\text { nition }\end{array}$ & 10 & 0,78 & 0,88 \\
\hline Performance Management & 9 & 0,78 & 0,88 \\
\hline Change Organizational Culture & 10 & 0,86 & 0,92 \\
\hline $\begin{array}{l}\text { Concepts \& Importance of In- } \\
\text { novation and Entrepreneurship }\end{array}$ & 6 & 0,84 & 0,91 \\
\hline Radical Innovation & 5 & 0,67 & 0,82 \\
\hline Incremental Innovation & 5 & 0,78 & 0,88 \\
\hline Total Reliability and Validity & 45 & 0,94 & 0,97 \\
\hline
\end{tabular}


than (3). The highest result is referring to rewards, benefits, and recognition variable $(4,16)$. Standard deviation (S.D.) presents the data stretch on or after the mean. Here also (S.D.) values are positive and lower than (1) which mean an obvious consistency from respondents toward variables. On the other hand, Skewness and kurtosis shows the normality of data which range from $(-1+1),(-3+3)$ respectively. Skewness values in this table for all variables lie in among the range so statistics is usual for these variables and right entered.

\section{Linear Relationship (Correlation) Test}

As a general rule, author will adopt the following classification for power of correlation between variables (Obaid. 2004):

$$
\begin{array}{llll}
{\left[0 \leq\left|r_{1 y}\right| \leq 0.3\right]} & \text { Poor } \quad\left[0.3 \leq\left|r_{1 y}\right| \leq 0.6\right] & \text { Moderate } \\
{\left[0.6 \leq r_{x y} \mid \leq 0.8\right]} & \text { Good } \quad\left[0.8 \leq\left|r_{x y}\right| \leq 1\right] & \text { Strong }
\end{array}
$$

\begin{tabular}{|c|c|c|c|}
\hline & & Frequen & rcentage \\
\hline \multirow{2}{*}{ Gender } & Male & 77 & 72,6 \\
\hline & Female & 29 & 27,4 \\
\hline \multirow{3}{*}{ Age } & $---<25$ & 31 & 29,3 \\
\hline & $26-45$ & 60 & 56,6 \\
\hline & $46<---$ & 15 & 14,1 \\
\hline \multirow{3}{*}{ Education } & Graduate & 70 & 66 \\
\hline & Master & 22 & 20,8 \\
\hline & $\mathrm{PhD}$ & 14 & 13,2 \\
\hline \multirow{3}{*}{ Position } & Supportive & 59 & 55,7 \\
\hline & Middle/Supervisor & 23 & 21,7 \\
\hline & Managerial & 24 & 22,6 \\
\hline \multirow{4}{*}{ Experience } & $1-4$ & 36 & 34 \\
\hline & $5-8$ & 28 & 26,4 \\
\hline & $9-12$ & 8 & 7,5 \\
\hline & $13<--$ & 34 & 32,1 \\
\hline
\end{tabular}

Table 2- Demographic Statistics

Values of table 4 point out there are positive and significant correlations between (HRM) functions and innovation \& entrepreneurship. A data show clearly there is a positive and strong correlation $(0,834)$ between the mentioned (HRM) functions and innovation \& entrepreneurship. Moreover, there is a positive and moderate correlation $(0,560)$ between rewards, benefits, and recognition and achieve innovation and being an entrepreneurship. In addition, there is a positive and good correlation $(0,725)$ between performance management and achieve innovation and being an entrepreneurship. All results disclose the need for more support toward (HRM) functions or policies to increase the level and type of innovations \& entrepreneurship.

\section{Results of Hypotheses (The Effect Test)}

Table 5 shows the positive effect between independent variable (HRM) functions and dependent variable (perceived innovation and then entrepreneurship) either on the macro or micro levels. On the macro level, based on $\left(\mathrm{R}^{2}\right)$ author can state (69\%) from the variance in the dependent variable could be explained by the (HRM) functions which tested in this article. Simultaneously, rest of the variance $(31 \%)$ definitely could be explained by different variables or functions. This fact is sustained by other vales such as: the calculated $(F)=(237,693)$ is greater than the tabulated $(F)=(6,964)$ on the mentioned

Table 3- Descriptive Examination

\begin{tabular}{lcccc}
\hline \multicolumn{1}{c}{ Variables } & Mean & $\begin{array}{c}\text { Standard } \\
\text { Deviation }\end{array}$ & Skewness & Kurtosis \\
\hline Rewards, Benefits, and Recognition & 4,16 &, 516 &,- 068 &,- 422 \\
\hline Performance Management & 4,03 &, 488 &,- 043 &,- 949 \\
\hline Change Organizational Culture & 4,05 &, 521 &,- 278 &, 114 \\
\hline $\begin{array}{l}\text { Concepts \& Importance of Innova- } \\
\text { tion and Entrepreneurship }\end{array}$ & 4,07 &, 452 &,- 099 &,- 709 \\
\hline Radical Innovation & 4,01 &, 615 &,- 364 &,- 123 \\
\hline Incremental Innovation & 4,07 &, 482 &,- 354 &,- 106 \\
\hline
\end{tabular}

Table 4- Linear Correlation Test between Variables

\begin{tabular}{lcc}
\hline \multirow{2}{*}{ Variables } & \multicolumn{2}{c}{ Innovation \& Entrepreneurship } \\
\cline { 2 - 3 } & Correlation (R) & Sig. \\
\hline (HRM) Functions (1+2) & $0,834^{* *}$ & 0,000 \\
\hline 1- Rewards, benefits, and recognition & $0,560^{* *}$ & 0,000 \\
\hline 2- Performance management & $0,725^{* *}$ & 0,000 \\
\hline **
\end{tabular}

** Correlation is significant at the $(0,01)$ level and $\mathrm{N}=106$

Table 5- Results of Regression Test between Some (HRM)

\begin{tabular}{|c|c|c|c|c|c|c|c|}
\hline \multirow{3}{*}{ Variables } & \multicolumn{7}{|c|}{ Innovation \& Entrepreneurship } \\
\hline & \multirow{2}{*}{$\mathrm{R}^{2}$} & \multirow{2}{*}{ D.F. } & \multicolumn{2}{|c|}{$F$} & \multirow{2}{*}{ B } & \multicolumn{2}{|c|}{$\mathrm{T}$} \\
\hline & & & Calculate & Tabulate & & Calculate & Tabulate \\
\hline $\begin{array}{l}\text { (HRM) Functions } \\
(1+2)\end{array}$ & 0,696 & $\begin{array}{c}1 \\
104 \\
\end{array}$ & 237,693 & 6,964 & 0,552 & 15,417 & 2,639 \\
\hline $\begin{array}{l}\text { 1- Rewards, bene- } \\
\text { fits, and recognition }\end{array}$ & 0,313 & $\begin{array}{c}1 \\
104 \\
\end{array}$ & 47,415 & 6,964 & 0,443 & 6,886 & 2,639 \\
\hline $\begin{array}{l}\text { 2-Performance } \\
\text { management }\end{array}$ & 0,526 & $\begin{array}{c}1 \\
104\end{array}$ & 115,475 & 6,964 & 0,637 & 10,746 & 2,639 \\
\hline
\end{tabular}

Functions Variable and Innovation \& Entrepreneurship Variable

Significant at the $(0,01)$ level. $\mathrm{N}=106$ 
degree of freedom and using the $(0,01)$ level of significance. Another support to the analysis, $(B)=(0,552)$ of the change in the dependent variable is a result of change in 1 unit of studied functions in (HRM). Last but not least, the calculated $(T)=(15,417)$ is greater than the tabulated $(T)=(2,639)$ on the mentioned degree of freedom. On the micro level, if we return to the same table and interpret the rows of each function separately. Author could logically repeat the same fact which stated: the positive effect is still running between....etc. But, there is a difference in the positive results of $R^{2}, F, B$, and $T$.

Derived from results of table 5, author accepts the null hypothesis:

- H1: Human resource functions (rewards, benefits, \& recognition and performance management) through change acceptance culture have statistically a significance effect on perceived innovations (radical and incremental) then entrepreneurship. And accepts the hypothesis:

- H2: Rewards, benefits, and recognition have statistically a moderate effect on perceived innovations (radical and incremental) then entrepreneurship. And accepts partially the hypothesis because the effect was positive and good not strong as proposed earlier:

- H3: Performance management has statistically a strong effect on perceived innovations (radical and incremental) then entrepreneurship.

\section{Conclusions}

This research attempted to fill this gap by analyzing the influence of these (HRM) functions on innovation and entrepreneurship. The findings indicated that rewards, benefits, \& recognition and performance management are significantly related to perceived innovations over time. This suggests that it is important that creativity and innovation researchers and practitioners examine all functions (policies) and procedures of (HRM) when conducting article on creativity, innovation, and entrepreneurship.

\section{Managerial Implications and Recommendations}

Results from this article have potentially vital implications for future practice and research. The results argue of examining some functions (or policies) of (HRM) when performing research on achieve innovation and then entrepreneurship. Therefore, these results provide empirical evidence to the theoretical models suggesting that innovation and entrepreneurship is impacted by (HRM).

An interesting aspect of the findings and results of this article is a comparison with aforementioned articles using different models, as well as using participant from a country (U.A.E.) other than western countries. Thus, the different results generated might also be attributed to these cultural differences.

Based on the results of this article, author can argue that for pharmaceutical organizations to crack down on all related functions and increase their investment with regards to innovation and entrepreneurship.

The article results show that pharmaceutical organizations need to ensure that rewards, benefits, \& recognition and performance management are designed such that it match really the ability level of innovation plans. This will help ensure that effective (HRMs) have the ability to allocate the required investments to the related function(s), and utilize the particular output accrued during innovation journey.

Also based upon the results, pharmaceutical organizations could achieve innovations by ensuring that human resource believe that they have the internal capabilities to successfully learn and freedom to apply their abilities. Organizational culture should be supportive and learning from mistakes encouragement because ones problem is another opportunities.

\section{Further Research}

As mentioned earlier, without the effective measurement of (HRM) functions from the innovation context or focus only on some functions the efforts of (HRM) will be general, vague, and outputs are simply mislead. Because it is no way to cover all functions of (HRM) as it deserve in single article, author already tested the rest functions in separate articles. Future research should examine pre and post application of (HRM) functions from innovation perspective in a similar article in order to determine if the functions prediction would provide same or better results. 


\section{References:}

Adner, R. (2012). The wide lens: A new strategy for innovation. Penguin England, London- UK, pp. 159. Akili, Omar Wasfi. (2005). Contemporary Human Resource Management. $1^{\text {st }}$ Arabic Edition. Dar Wael for Publishing Inc., Amman- Jordan, ISBN: 9957-11-498-0.

- $\quad$ Anderson, Neil; Potočnik, Kristina and Zhou Jing. (2014). "Innovation and creativity in organizations: A state-of-the-science review: Prospective commentary and guiding framework", Journal of Management, Vol. 40, No. 5, pp. 1297-1333.

- $\quad$ Aryee, S.; Walumbwa, F. O.; Seidu, E. Y. and Otaye, L. E. (2012). "Impact of high-performance work systems on individual- and branch-level performance: Test of a multilevel model of intermediate linkages", Journal of Applied Psychology, Vol. 97, No. 2, pp. 287-300.

- $\quad$ Baer, M. and Frese, M. (2003). "Innovation is not enough: Climates for initiative and psychological safety, process innovations and firm performance", Journal of Organizational Behavior, Vol. 24, pp. 45-68.

- Bonazzi, Fábio Luiz Zandoval and Zilber, Moises Ari. (2014). "Innovation and business model: A case study about integration of Innovation funnel and business model canvas, revista Brasileira de gestao de negocios (RBGN)", Review of Business Management, ISSN 1806-4892, Vol. 16, No. 53, pp. 616-637.

- Boston Consulting Group. (2006). Innovation 2006. online: www.bcg.com/publications/ files/2006_Innovation_Survey_report.pdf

- $\quad$ Bruton, Garry and Margaret, White. (2011). Strategic Management of Technology and Innovation. $2^{\text {nd }}$ Edition. South Western, Cengage learning printed in Canada, pp. 111.

Chang, P. C. and Chen, S. J. (2011). "Crossing the level of employee's performance: HPWS, affective commitment, human capital, and employee job performance in professional service organizations, International", Journal of Human Resource Management, Vol. 22, No. 4, pp. 883-901.

- Chen, Chung-Jen and Huang, Jing-Wen. (2007). "How organizational climate and structure affect knowledge management: The social interaction perspective", International Journal of Information Management, Vol. 27, No. 2, pp. 104-118.

- Chesbrough, H .W. (2003). "The era of open innovation", MIT Sloan Management Review, Cambridge. Vol. 44, No. 3, pp. 34-41.

- Czarnitzki, D. and Thorwarth, S. (2012). "The contribution of in house and external design activities to product market performance", Journal of Product Innovation Management, Vol. 29, pp. 878-895.

- Damanpour, F. and Wischnevsky, J. D. (2006). "Research on innovation in organizations: Distinguishing innovation-generating from innovation-adopting organizations", Journal of Engineering and Technology Management, Vol. 23, pp. 269-291.

- Dan Dalotă, Marius and Perju, Alexandra. (2010). "Human resource management and the company`s innovation", Romanian Economic and Business Review, Vol. 5, No. 4, pp. 122-131.

- Drucker, Peter. (2007). Innovation and Entrepreneurship: Practice and Principles. Revised edition. Oxford- UK.

- $\quad$ Du Preez, N.D. and Louw, L. (2008). "A framework for managing the innovation process", Portland International Conference: Management of Engineering \& Technology (PICMET 2008), 27-31 July, Cape Town-_South Africa. pp. 546-558.

- EU European Commission. (2004). Innovation Management and the Knowledge- Driven Economy. Directorate-general for enterprise, Brussels- Belgium.

- $\quad$ Fauchart, Emmanuelle and Gruber, Marc. (2011). "Darwinians, communitarians, and missionaries: The role of founder identity in entrepreneurship", Academy of Management Journal, Vol. 54, No. 5, pp. 935-957.

Filippetti, A. and Archibugi, D. (2011). "Innovation in times of crisis: National systems of innovation, structure, and demand", Research Policy, Vol. 40, pp. 179-192. 
Francis, Dave and Bessant, John. (2005). "Targeting innovation and implications for capability development", Technovation, Vol. 25, No. 3, pp.171-183.

Freeman, Chris. (1982). The Economics of Industrial Innovation. $2^{\text {nd }}$ Edition. Frances printers. London- UK.

Gambatese, J. A. and Hallowell, M. (2011). "Enabling and measuring innovation in the construction industry", Construction Management and Economics, Vol. 29, pp. 553-567.

- Gomez-Mejia, L. R.; Balkin, D. B. and Cardy, R. L. (2004). Managing Human Resource. Prentice Hall Inc., Upper Saddle River, New Jersey- USA.

Griffiths, Steve and Moavenzadeh, Fred. (2015). "Research and innovation", Paper presented at: Masdar Institute and MIT Collaborative Research Conference, 13 April, Abu Dhabi- UAE.

- Hobday, M.; H. Rush et al. (2005). "Reaching the innovation frontier in Korea: A new corporate strategy dilemma", Research Policy, Vol. 33, pp. 1433-1457.

- Janssen, O.; Van de Vliert, E. and West, M. A. (2004). "The bright and dark sides of individual and group innovation: A special issue introduction", Journal of Organizational Behavior, Vol. 25, pp. 129-145.

- Jiménez-Jiménez, Daniel and Sanz-Valle, Raquel (2005). "Innovation and human resource management fit: an empirical study", International Journal of Manpower, Vol. 26, No. 4, pp. 364-381.

- Jiménez-Jiménez, Daniel and Sanz-Valle, Raquel. (2011). "Innovation, organizational learning, and performance", Journal of Business Research, Vol. 64, No. 4, pp. 408-417.

- Jones, T.; McCormick, D.; and Dewing, C. (2012). Growth Champions: The Battle for Sustained Innovation Leadership. John Wiley \& Sons Ltd., Chichester, West Sussex- UK.

- Jung, D.; Wu, A.; and Chow, C. W. (2008). "Towards understanding the direct and indirect effects of CEOs' transformational leadership on firm innovation", The Leadership Quarterly, Vol. 19, pp. 582-594.

- $\quad$ Kemp, RGM.; Folkeringa, M.; De Jong, JPJ.; and Wubben, EFM. (2003). "Innovation and firm performance", Research Report-H200207, ISBN: 90-371-0875-X.

- Kobe, Carmen and Goller, Ina. (2014). Four approaches to fostering companies' innovation capability". Innovation management.se, online: http://www.innovationmanagement.se/2011/06/29/four-approaches-to-fostering-companies-innovation-capability/

- Langerak, F. and Hultink, E. J. (2008). "The effect of new product development acceleration approaches on development speed: A case study", Journal of Engineering and Technology Management, Vol. 25, pp. 157-167.

- $\quad$ Laursen, K. and Foss, N. J. (2003). "New human resource management practices, complementarities and the impact on innovation performance", Cambridge Journal of Economics, Vol. 27, pp. 243263.

- $\quad$ Lawson, B. and Samson, D. (2001). "Developing innovation capability in organizations: A dynamic capabilities approach", International Journal of Innovation Management, Vol. 5, No. 3, pp. 377-400.

- Leifer, R.; McDermott, C.; and et al. (2000). Radical Innovation. Harvard Business School Press, Boston MA- USA.

- Loof, H. and Heshmati, A. (2002). On the relationship between innovation and performance: sensitivity analysis. Royal institute of technology, Industrial economics and management, The United Nation University, UNU/WIDER.

- Manu, Alexander. (2010). Disruptive Business: Desire, Innovation and the redesign of Business. Gower publishing limited, ISBN: 978-0-566-09240-4. Farnham, Surry- UK. pp. 10-13.

- Mariotti, Steve and Glackin, Caroline. (2012). Entrepreneurship \& Small Business Management. Pearson education inc., Upper saddle river, New Jersey- USA, pp. 530-538. 
Mark, S. K. M. and Akhtar, S. (2003). "Human resource management practices, strategic orientation, and company performance: A correlation study of publically listed companies", Journal of American Academy of Business, Vol. 2, No. 2, pp. 510-525.

McClean, E. and Collins, C. J. (2011). "High-commitment HR practices, employee effort, and firm performance: Investigating the effects of HR practices across employee groups within professional services firms", Human Resource Management, Vol. 50, No. 3, pp. 341-363.

Mothe, C. and Nguyen Thi, T. U. (2012). "Non technological and technological innovations...? An empirical analysis of Luxembourg firms", International Journal of Technology Management, Vol. 57, No. 4, pp. 227-244.

Mumford, M. D. (2000). "Managing creative people: Strategies and tactics for innovation", Human Resource Management Review, Vol. 10, No. 3, pp. 313-351.

Naser, Mohamed. (2017). "The link between some HRM functions and importance of implementing Innovations (Radical-Incremental) for being an entrepreneurship, Paper presented at: Innovation Arabia10 ${ }^{\text {th }}$ Annual Conference, Dubai- UAE.

Nasser, Ahmad and Abuzaid, Ahmad. (2014). "The impact of strategic alliance partner characteristics on firms innovation: Evidence from Jordan", International Journal of Business and Management, Vol. 9, No. 3, pp.77-87.

Navarro, J. J. Mikel; Osorio, B. Bilbao and Aguado, R. (2009). "Environment and planning", Government and Policy Journal, Vol. 27, pp. 815-840.

Nor'Aini Yusof; Ernawati Kamal; Kong-Seng Lai and Iranmanesh Mohammad. (2014). Are innovations being created or adopted in the construction industry? exploring innovation in the construction Industry, SAGE open (sgo.sagepub.com), Vol. July-September, pp.1-9. Online: http://www.uk.sagepub.com/aboutus/openaccess.htm

- O`Connor, G.; Paulson, A. et al. (2008). Grabbing Lightning. Jossey Bass, San Francisco, CA- USA.

- Obaid, Abdurrahman Ahmed. (2004). Principles of managerial forecasting. Arabic Edition. King Saud university Press, Riyadh- Kingdom of Saudi Arabia, pp. 60.

- $\quad$ Patterson, M. G.; West, M. A.; Shackleton, V. J.; Dawson, J. F.; Lawthom, R.; Maitlis, S.; Robinson, D. L.; and Wallace, A. M. (2005). "Validating the organizational climate measure: Links to managerial practices, productivity, and innovation", Journal of Organizational Behavior, Vol. 26, pp. 379-408.

- $\quad$ Philips, W.; Noke, H. et al. (2006). "Beyond the steady state: Managing discontinuous product and process innovation", International Journal of Innovation Management, Vol. 10, No. 2, pp. 175196.

- $\quad$ Popadiuk, S. and Choo, C. W. (2006). "Innovation and knowledge creation: How are these concepts related?", International Journal of Information Management, Vol. 26, pp. 302-312.

- $\quad$ Porter, Michael. (1990). The Competitive Advantage of Nations. Macmillan. London- UK.

- Pérez-Luño, A.; Wiklund, J. and Cabrera, R. V. (2011). "The dual nature of innovative activity: How entrepreneurial orientation influences innovation generation and adoption", Journal of Business Venturing, Vol. 26, pp. 555-571.

- $\quad$ Rayen, Lourdes and Ani, J. Jaya. (2014). Creativity and Innovation. Discovery Publishing House PVT Ltd., New Delhi- India, pp. 187-203.

- Razavi, Seyed Hadi and Attarnezhad, Omid. (2013). "Management of organizational innovation", International Journal of Business and Social Science, Vol. 4, No. 1, pp. 226-232.

- $\quad$ Saleh, S. D. and Wang, C. K. (1993). "The Management of innovation: Strategy, structure and organizational climate", IEEE Transactions on Engineering Management, Vol. 40, No. 1, pp. 14-21.

- Schilling, M. A. (2008). "Understanding the alliance data", Strategic Management Journal, Vol. 30, No. 3, pp. 233-260.

- $\quad$ Schumpeter, Joseph. (1950). Capitalism, Socialism and Democracy. $3^{\text {rd }}$ ed. Harper and Row Inc., New York- USA. 
Sekaran, Uma and R. Bougie. (2013). Research Method for Business: A Skill Building Approach. $6^{\text {th }}$ Edition. GAO, Government Auditing Standards.

- $\quad$ Shrivastave, S. and Shaw, J. B. (2004). "Liberating HR through technology", Human Resource Management, Vol. 42, No. 3, pp. 201-220.

- Stapenhurst, T. (2012). The Benchmarking Book: Best Practice for Quality Managers and Practitioners. Routledge, New York-USA.

- Suhag, Abdul karim Shafique; Solangi, Rahman; Larik, Raja Sohail Ahmed; Lakh, Muhammad Kamil; and Tagar, Altaf Hussain. (2017). "Relationship of innovation with organizational performance", International Journal of Research-Granthaalayah, Vol. 5, No. 2, pp. 292-306. https://doi. org/10.5281/zenodo.345736

- $\quad$ Szymanski, D.; Kroff, M. and Troy, L. (2007). "Innovativeness and new product success: Insights from the cumulative evidence", Journal of the Academy of Marketing Science, Vol. 35, pp. 35-52.

- $\quad$ Tidd, Joe and Bessant, John. (2014). Managing Innovation: Integrating Technological, Market, and Organizational change. $5^{\text {th }}$ ed. John Wiley \& Sons Ltd., Chichester, West Sussex- UK. Printed in Italy, pp. 4-11

- Van der Panne, Gerban; Van beers, Cees and Kleinknecht, Alfred. (2003). "Success and failure of innovation: A review of the literature", International Journal of Innovation Management, Vol. 7, No. 3, pp.309-338

- Wang, Zhongming. (2003). "Chinese models of entrepreneurship and strategic human resource", Paper presented at the International Conference on Managing HR in the high growth firms, 14-15 February, Columbus-Ohio.

- Wang, Zhongming and Zang, Zhi. (2005). "Strategic human resources, Innovation and entrepreneurship fit: A cross-regional comparative model", International Journal of Manpower, Vol. 26, No. 6, pp. 544-559.

- Zhou, K. Z. (2006). "Innovation, Imitation, and new product performance: The case of china", Industrial Marketing Management, Vol. 35, pp. 394-402. 